\title{
APLIKASI PENGENALAN DINOSAURUS DENGAN ANIMASI 3D BERBASIS ANDROID MENGGUNAKAN AUGMENTED REALITY (AR)
}

\author{
1)Avysa Nabila, ${ }^{2)}$ Muhammad Imron Rosadi \\ ${ }^{1,2)}$ Teknik informatika, Universitas Yudharta Pasuruan. \\ ${ }^{1,2)}$ Pasuruan, Jawa Timur 67162 \\ 1)azyvapitsburg@gmail.com, ${ }^{2)}$ imron.rosadi@yudharta.ac.id
}

\begin{abstract}
ABSTRAK
Peningkatan di sekolahan pada umumnya proses pendidikan hampir sama, adanya pemberian materi menggunakan media-media seperti, papan tulis, buku-buku bergambar yang digunakan untuk lebih memperjelas materi kepada siswa. Aplikasi yang dikembangkan dan telah dipasang pada perangkat Android dengan menggunakan Vuforia sebagai dukungan teknologi Augmented Reality. Munculnya teknologi Augmented Reality sangat membantu prosesnya pendidikan pengenalan hewan terutama dengan adanya dukungan terhadap marker yang memadukan buku 2D sebagai marker untuk memunculkan objek 3D. Saat ini untuk belajar mengenai hewan Dinosaurus ketika belajar sejarah di sekolah setingkat SD dan SMP hanya dapat dipelajari dari buku sejarah saja, dimana terdapat gambar fosil Dinosaurus yang telah ditemukan di berbagai dunia. Dari pembahasan dapat disimpulkan bahwa perangkat Smartphone dan menggunkan Augmented Reality (AR), bisa dimanfaatkan sebagai media untuk mendapatkan informasi tentang jenis-jenis hewan dengan lebih mudah, efektif dan interaktif.
\end{abstract}

Kata kunci : Augmented Reality, Dinosaurus, Android, Vuforia

\section{ABSTRACT}

Improvement in schools in general the process of education is almost the same, the provision of material using media such as, blackboards, picture books are used to further clarify the material to students. Application developed and has been installed on Android devices using Vuforia as support for Augmented Reality technology. The emergence of Augmented Reality technology is very helpful in the process of animal recognition education especially with the support of marker which combines 2D books as markers to bring up 3D objects. Currently to learn about dinosaurs when studying history in elementary and junior high schools can only be learned from history books, where there are pictures of dinosaur fossils that have been found in various worlds. From the discussion it can be concluded that the Smartphone device and using Augmented Reality (AR), can be used as a medium to get information about types of animals more easily, effectively and interactively.

Keywords : Augmented Reality, Dinosaur, Android, Vuforia

\section{PENDAHULUAN}

Peningkatan di sekolahan pada umumnya proses pendidikan hampir sama, adanya pemberian materi menggunakan media-media seperti, papan tulis, buku-buku bergambar yang digunakan untuk lebih memperjelas materi kepada siswa (Untiarasani, 2015).

Munculnya teknologi Augmented Reality sangat membantu prosesnya pendidikan pengenalan dinosaurus terutama dengan adanya dukungan terhadap marker yang memadukan buku 2 Dimensi sebagai marker untuk memunculkan objek 3 Dimensi. Aplikasi yang dikembangkan dan telah dipasang pada perangkat Android dengan menggunakan Vuforia sebagai dukungan teknologi Augmented Reality (Calros Laorden, 2012).

Dalam mengenal makhluk hidup seperti dinosaurus bisa dikatakan penting. Pentingnya menanamkan kecintaan terhadap makhuk hidup kepada anak -anak. Fauna yang dikenalkan termasuk fauna domestic atau yang bisa disebut dinosaurus jinak atau peliharaan. Dinosaurus peliharaan adalah dinosaurus yang biasanya lebih banyak berada di sekitaran manusia (Harizenputri, 2017). Achmad yunus dan Lukman hakim (2015) membuat aplikasi berbasis android untuk pembelajaran bahasa arab menggunakan speech recognition.

Namun memilih mainan perlu didasari dengan banyak pertimbangan. Hal ini dikarenakan mulai banyak mainan yang tidak sesuai dengan badan standar nasional mainan anak yang mengandung zat kimia yang dapat berdampak pada kesehatan anak. Selain itu tampilan bentuk fisik mainan edukasi dalam berbagai macam tidak aman untuk anak. Persoalan baca, tulis dan hitung menjadi isu penting karena laporan IEA Study of Reading Literacy (et.al, 2015) menyatakan bahwa kemampuan anak sekolah dasar di Indonesia sangat rendah. 
Berdasarkan latar belakang tersebut maka penelitian ini diwujudkan sebagai bahan penyusunan skripsi dengan judul : "APLIKASI PENGENALAN DINOSAURUS DENGAN ANIMASI 3D BERBASIS ANDROID MENGGUNAKAN AUGMENTED REALITY (AR)".

\subsection{Rancangan Sistem}

\section{METODE PENELITIAN}

Penelitian ini menggunakan metode waterfall dalam pembuatan aplikasi android game edukasi ini dengan fitur notifikasi. Pengerjaan aplikasi akan dilakukan secara berurutan. Urutan atau tahapannya adalah analisis, desain, kode, dan test.

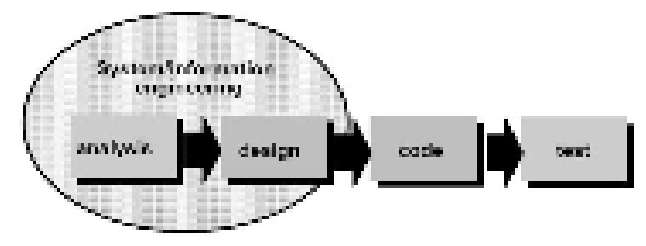

Gambar2.1 Tahapan Metode Waterfall

\subsection{Use Case Diagram}

Merujuk pada flowchart sistem aplikasi Augmented Reality yang sudah digambarkan sebelumnya maka dapat dibuat use case diagram berikut juga spesifikasi dari use case diagram.

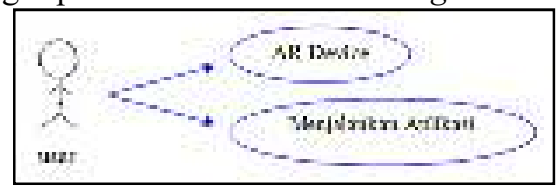

Gambar 2.2 Use Case Sistem Aplikasi

\subsection{Flowchart}

Gambaran dalam bentuk diagram alir dari algoritma-algoritma dalam suatu program. Bagian ini merupakan proses untuk memasukkan data ke komputer melalui device yang ada. Diagram alir dari sistem yang akan penulis bangun adalah sebagai berikut:

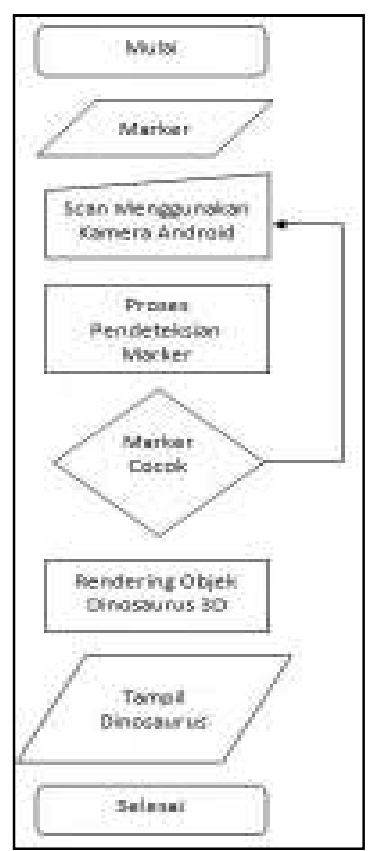

Gambar 2.3 Flowchart

\subsection{Desain Dinosaurus}


Desain dinosaurus yang dimaksud disini adalah membuat gambar dalam bentuk 3D yang berguna untuk menampilkan gambar 3D pada android ketika marker (target gambar) terdeteksi dengan benar.

Adapun desain 3D untuk membuat dinosaurus pada penelitian ini menggunakan aplikasi blender-2.79b. berikut ini adalah layout contoh desain 3D dinosaurus.

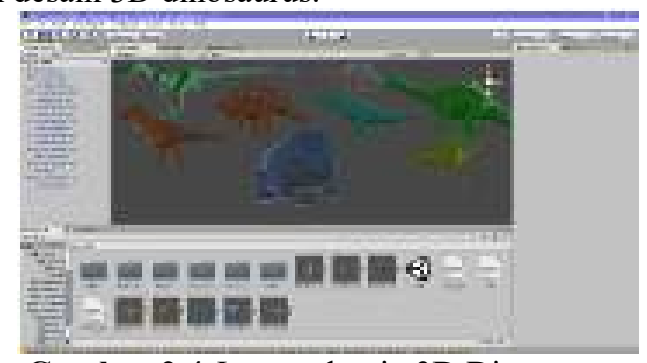

Gambar 2.4 Layout desain 3D Dinosaurus

\subsection{Pembuatan Marker}

Dalam membuat marker yang akan digunakan, maka akan diperlukan sebuah file gambar yang berformat JPG dan gambar tersebut akan di upload ke database vuforia. Marker yang akan dibuat bernama image target. Image target adalah gambar yang dapat di deteksi dan dilacak oleh vuforia SDK. Jenis gambar tidak seperti marker tradisional seperti data matrix code dan QR codes, marker juga tidak perlu warna hitam dan putih yang berdesain khusus untuk dikenali.

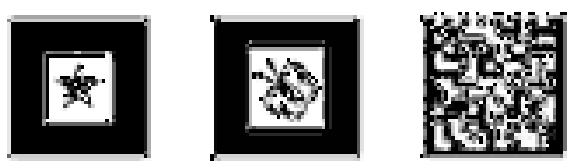

Gambar 2.5 Contoh Marker Tradisional

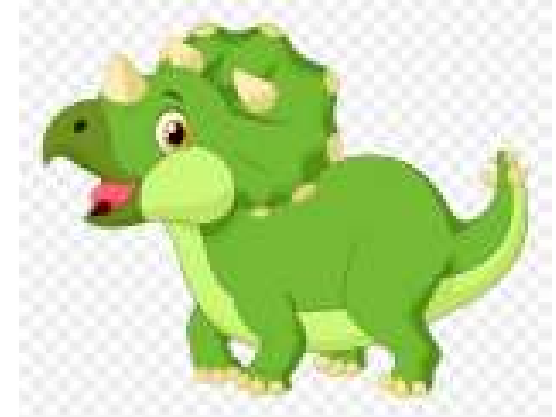

Gambar 2.6 Contoh Marker non-Tradisional

Marker atau juga disebut image target merupakan gambar yang digunakan sebagai target utama dalam memunculkan Augmented Reality. Merker akan diproses pada Unity 3D dan dibuat menggunakan sebuah gambar.

\subsection{Upload Marker Ke Vuforia}

Image hasil editan yang sudah dilakukan di blender akan di upload ke website vuforia. File yang telah diupload tersebutakan dinilai kualitasnya oleh sistem. Semua marker yan telah di upload akan menghasilkan sebuah source code (hasil dari gambar setelah digenerate vuforia) berupa file xml. File xml ini merupakan file konfigurasi dari vuforia terhadap marker-marker yang telah diupload. Langkah-langkah pembuatan marker lengkapnya seperti berikut ini :

1. Masuk ke website vuforia www.developer.vuforia.com 
JURNAL EXPLORE IT!

Vol. 11 No. 2 - Desember 2019

p-ISSN 2086-3489 (Print)- e-ISSN 2549-354X (Online)

Avaiable online at http://jurnal.yudharta.ac.id/v2/index.php/EXPLORE-IT/

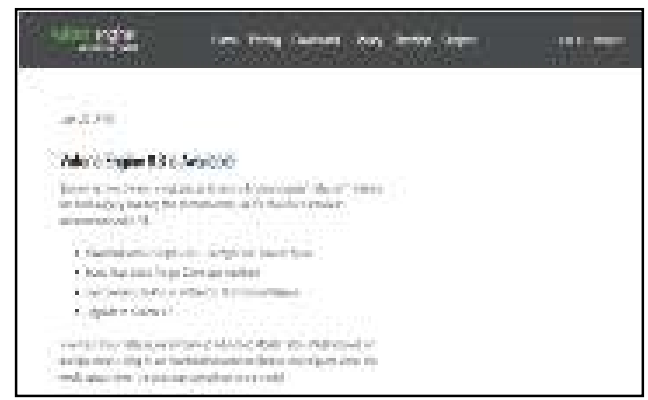

2. Login terlebih dahulu

Gambar 2.7 Halaman Utama Website Vuforia

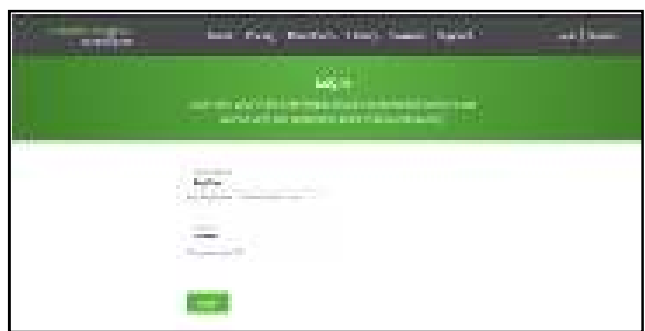

Gambar 2.8 Tampilan Login Vuforia

Sebelum login vuforia pastikan anda sudah memiliki akun vuforia terlebih dahulu.

3. Setelah berhasil login pilih menu develop lalu klik sub menu target manager

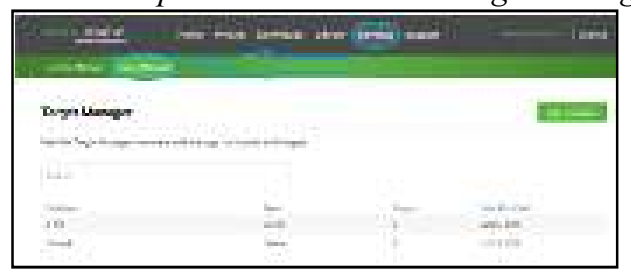

Gambar 2.9 Halaman Dashboard User

4. Setelah itu klik Add Database untuk mengupload marker

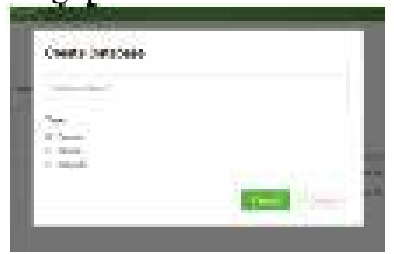

5. Hasil upload marker

Gambar 2.10 Create Database

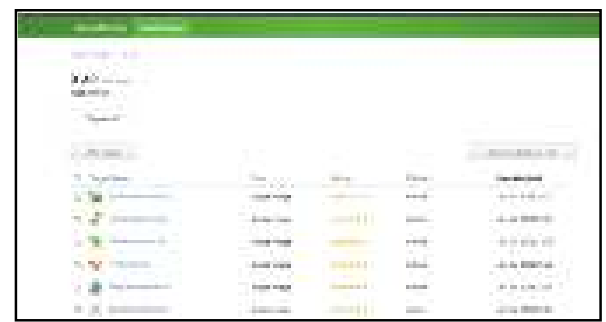

Gambar 2.11 Marker Yang Sudah di Upload

Bintang pada kolom ranking menentukan kualitas gambar yang digunakan sebagai marker.

6. Download marker dari vuforia 


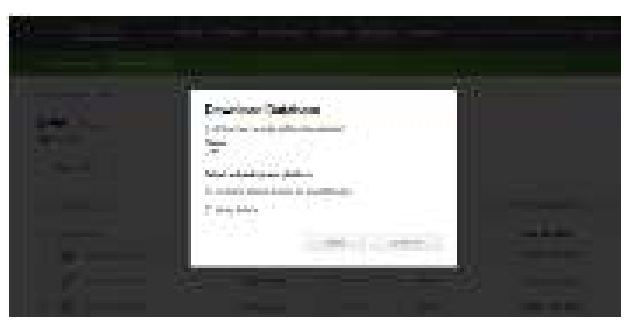

Gambar 2.12 Tampilan Download Marker

Marker yang sudah di upload ke vuforia selanjutnya akan di download dan di import ke unity.

7. Import marker ke Unity

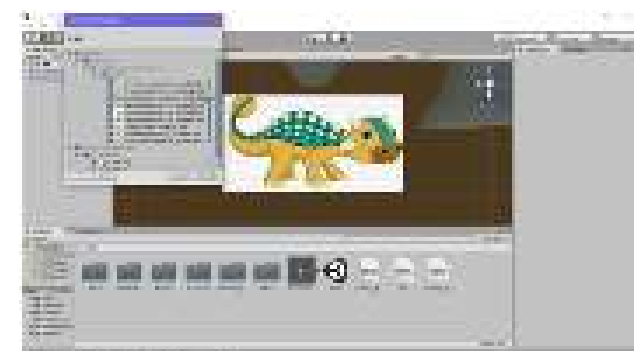

Gambar 2.13 Tampilan Import Marker Ke Unity

Selanjutnya marker yang sudah di download akan di import ke unity untuk di ekstrak.

\section{HASIL DAN PEMBAHASAN}

\subsection{Cara Penggunaan Aplikasi}

Disini akan dijelaskan langkah-langkah mulai dari penginstalan dan cara menggunakan aplikasi pengenalan dinosaurus. Langkah-lankgkahnya sebagai berikut :

1. Instal aplikasi Pengenalan Dinosaurus di Smartphone android dan tunggu hingga proses penginstalan selesai.

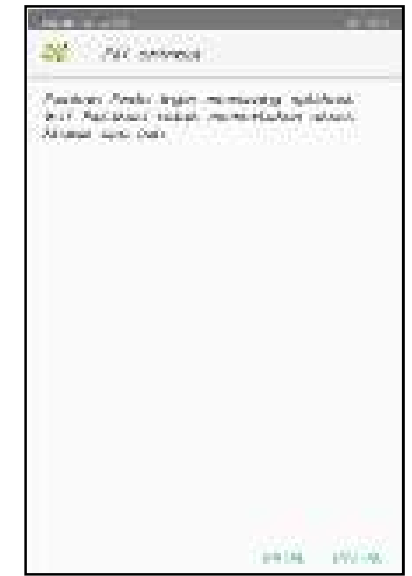

Gambar 3.1 Tampilan untuk Meng-install Aplikasi 
JURNAL EXPLORE IT!

Vol. 11 No. 2 - Desember 2019

p-ISSN 2086-3489 (Print)- e-ISSN 2549-354X (Online)

Avaiable online at http://jurnal.yudharta.ac.id/v2/index.php/EXPLORE-IT/

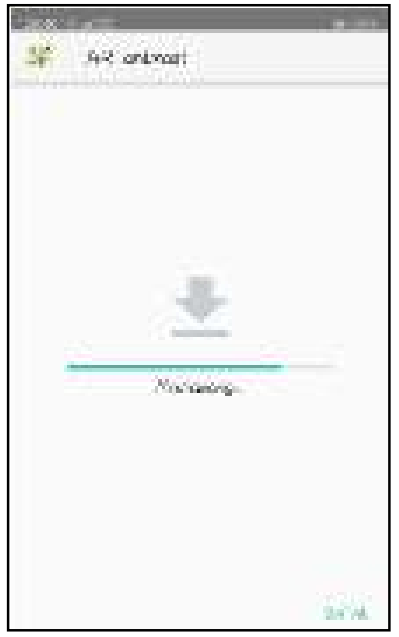

Gambar 3.2 Proses Instalasi Aplikasi

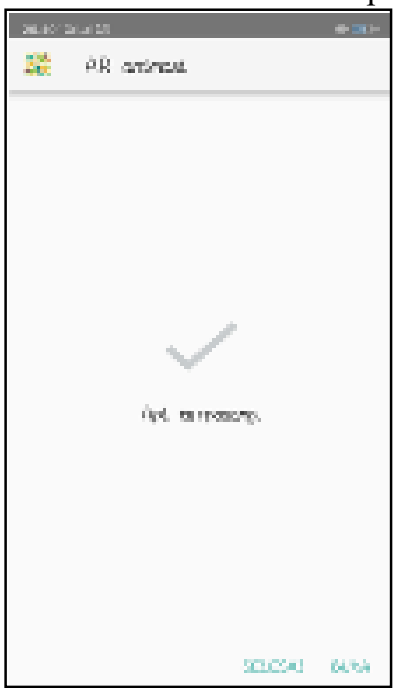

Gambar 3.3 Tampilan Aplikasi Ter-install

2. Jalankan aplikasi yang telah terinstal di Smartphone dan akan muncul splashscreen seperti ini.

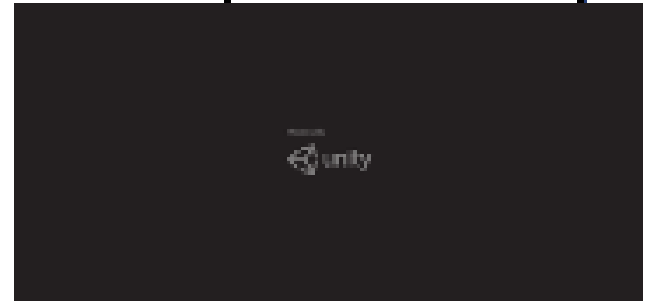

Gambar 3.4 Tampilan Awal Aplikasi

3. Tampil menu utama aplikasi pengenalan dinosaurus.

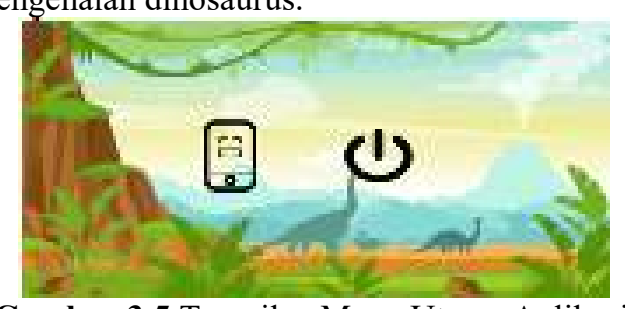

Gambar 3.5 Tampilan Menu Utama Aplikasi

Tampilan menu utama memiliki empat tombol yaitu tombol mulai kamera, dan keluar. Ketika tombol mulai diklik, akan mengakses kamera android dan menampilkan desain dinosaurus berbentuk 3D pada marker yang sudah 
didefinisikan. Saat desain dinosaurus muncul disana akan muncul tombol info dan apabila tombol itu diklik atau ditekan maka akan keluar deskripsi dari dinosaurus tersebut. Aplikasi akan mendeteksi marker satu persatu dan tidak akan menampilkan desain 3D apabila tidak diarahkan ke marker dengan tepat.

4. Pilih tombol mulai kamera dan arahkan kamera ke marker yang telah disiapkan.

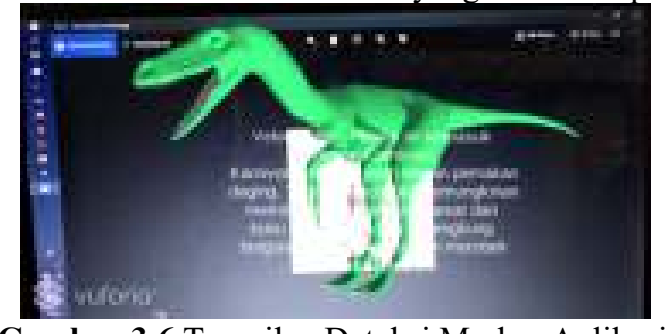

Gambar 3.6 Tampilan Deteksi Marker Aplikasi

\subsection{Pengujian Aplikasi}

Pengujian aplikasi ini menggunakan teknik pengujian black box. Dimana pada tahap ini akan menguji fungsionalitas dari fitur-fitur yang disediakan aplikasi.

Tabel 3.1 Tabel Pengujian Fungsionalitas

\begin{tabular}{|c|c|c|c|c|}
\hline No & Pengujian & $\begin{array}{l}\text { Hasil yang } \\
\text { diharapkan }\end{array}$ & $\begin{array}{c}\text { Hasil } \\
\text { Pengujian }\end{array}$ & Kesimpulan \\
\hline 1 & $\begin{array}{l}\text { Instal } \\
\mathrm{APK} \\
\text { (Master) }\end{array}$ & $\begin{array}{l}\text { Proses } \\
\text { instalasi dan } \\
\text { terpasang } \\
\text { pada } \\
\text { smartphone } \\
\text { android } \\
\text { dengan baik }\end{array}$ & $\begin{array}{l}\text { Sesuai } \\
\text { harapan }\end{array}$ & Valid \\
\hline 2 & $\begin{array}{l}\text { Menjalan- } \\
\text { kan } \\
\text { aplikasi } \\
\text { yang } \\
\text { terpasang }\end{array}$ & $\begin{array}{l}\text { Berjalan } \\
\text { dan aplikasi } \\
\text { dapat } \\
\text { terbuka } \\
\text { dengan baik }\end{array}$ & $\begin{array}{l}\text { Sesuai } \\
\text { harapan }\end{array}$ & Valid \\
\hline 3 & $\begin{array}{l}\text { Pendeteksi } \\
\text { marker } \\
\text { yang } \\
\text { berbeda }\end{array}$ & $\begin{array}{l}\text { Tidak dapat } \\
\text { keluar objek } \\
\text { dinosaurus } \\
\text { 3D }\end{array}$ & $\begin{array}{l}\text { Sesuai } \\
\text { harapan }\end{array}$ & Valid \\
\hline 4 & $\begin{array}{l}\text { Pendeteksi } \\
\text { an marker } \\
\text { yang sama } \\
\text { dan yang } \\
\text { telah } \\
\text { ditentukan }\end{array}$ & $\begin{array}{l}\text { Keluar } \\
\text { objek } \\
\text { dinosaurus } \\
\text { 3D }\end{array}$ & $\begin{array}{l}\text { Sesuai } \\
\text { harapan }\end{array}$ & Valid \\
\hline 5 & $\begin{array}{l}\text { Tombol } \\
\text { Mulai } \\
\text { Kamera } \\
\text { diklik }\end{array}$ & $\begin{array}{l}\text { Mengakses } \\
\text { kamera } \\
\text { ketika } \\
\text { diarahkan } \\
\text { ke marker } \\
\text { dapat } \\
\text { menampil- } \\
\text { kan Objek } \\
\text { 3D } \\
\text { Dinosaurus }\end{array}$ & $\begin{array}{l}\text { Sesuai } \\
\text { harapan }\end{array}$ & Valid \\
\hline
\end{tabular}

\subsection{Pengujian Berdasarkan Spesifikasi Smartphone}

Berikut ini adalah daftar smartphone yang telah diinstal aplikasi pengenalan dinosaurus yang digunakan untuk menguji aplikasi.

Tabel 3.2 Perangkat Penguji Aplikasi 


\begin{tabular}{|c|c|c|}
\hline 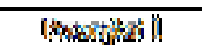 & $8 x=60,5,2$ & phowkzis \\
\hline 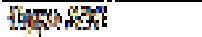 & growats ath & 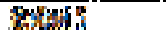 \\
\hline 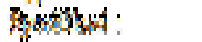 & 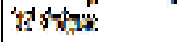 & 9oxtrow \\
\hline हैंspswn & 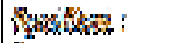 & Rिक्षan Q4y \\
\hline 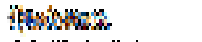 & Qhasents & $16 n$ \\
\hline 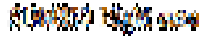 & 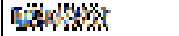 & Q \\
\hline 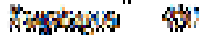 & pianchere & sind \\
\hline 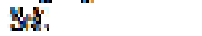 & anteres sos & 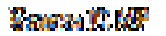 \\
\hline 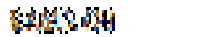 & scivestent? & 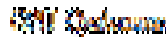 \\
\hline 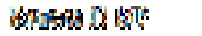 & estosisu & Mkx:2w \\
\hline 6atures & 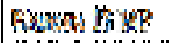 & 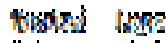 \\
\hline Shas 等家 & 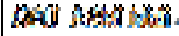 & iyl? \\
\hline 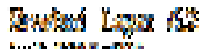 & Ton bers 34 & 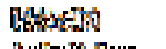 \\
\hline 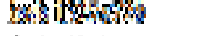 & 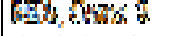 & 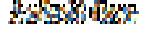 \\
\hline 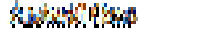 & 敒: & \\
\hline & 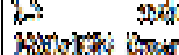 & \\
\hline & wo & \\
\hline & 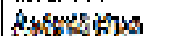 & \\
\hline
\end{tabular}

Pada gambar diatas merupakan hasil pengujian respon time loading kamera smartphone. Pada pengujian ini dapat disimpulkan bahwa semakin tinggi spesifikasi device smartphone terutama pada RAM dan prosesor maka loading pada kamera dalam aplikasi akan berjalan lebih cepat.

Tabel 3.3 Pengujian Respon Time Aplikasi

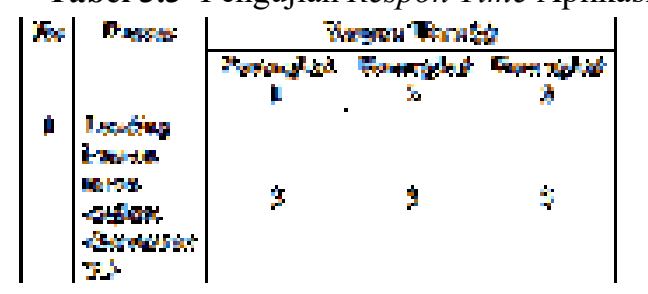

Berdasarkan tabel 3.3 dapat disimpulkan bahwa perangkat 1 mampu mendeteksi marker membutuhkan waktu 5 detik, perangkat 2 membutuhkan waktu 5 detik dan perangkat 3 membutuhkan waktu 3 detik.

\section{KESIMPULAN}

1. Hasil pengujian fungsionalitas dan pengujian jarak aplikasi pengenalan dinosaurus berjalan dengan baik.

2. Apliksi ini memiliki presentase kelayakan sebesar $80.35 \%$. dapat disimpulkan bahwa kualitas aplikasi AR pengenalan dinosaurus memiliki kategori "LAYAK".

3. Proses pengenalan marker berpengaruh terhadap kamera smartphone, faktor cahaya, fokus, dan rating marker. Dalam pendeteksian marker harus mendapatkan cahaya langsung tanpa terhalangi benda lain agar dapat terdeteksi secara normal.

4. Aplikasi ini akan menampilkan ukuran baik gambar atau tulisan yang berbeda pada device smartphone yang berbeda pula, tergantung dari resolusi layar smarphone.

\section{DAFTAR PUSTAKA}

[1] Calros Laorden, P. G. (2012). A Human-Computer Interaction Paradigm for Augmented Reality Systems.

[2] et.al, D. (2015). Perancangan Aplikasi Game Edukasi Pembelajaran Anak Usia Dini Menggunakan Linear Congruent Method ( Lcm ) Berbasis Android. Jurnal Informatika Global, 7-14. 
JURNAL EXPLORE IT!

Vol. 11 No. 2 - Desember 2019

p-ISSN 2086-3489 (Print)- e-ISSN 2549-354X (Online)

Avaiable online at

http://jurnal.yudharta.ac.id/v2/index.php/EXPLORE-IT/

[3] Harizenputri, A. A. (2017). Anlos Mainan Edukasi Pengenalan Hewan untuk Usia 3-5 Tahun. 1574.

[4] Untiarasani, M. Q. (2015). Pembangunan Perangkat Lunak Interaktif Berbasis Markerless Augmented Reality Untuk Pengenalan Hewan Pada Taman Kanak. Techno. Com, 159-164.

[5] L. Hakim and A. Yunus, "Implementasi Speech Recognition Dalam Aplikasi Pembelajaran Bahasa Arab Untuk Anak Usia Dini Berbasis Android”, EXPLORIT, vol. 10, no. 2, pp. 41-49, Jan. 2019. 